\title{
Geoelectric hazard assessment: the differences of geoelectric responses during magnetic storms within common physiographic zones
}

\author{
Stephen W. Cuttler ${ }^{1 *}$, Jeffrey J. Love ${ }^{2}$ and Andrei Swidinsky ${ }^{1}$
}

\begin{abstract}
Geomagnetic field data obtained through the INTERMAGNET program are convolved with with magnetotelluric surface impedance from four EarthScope USArray sites to estimate the geoelectric variations throughout the duration of a magnetic storm. A duration of time from June 22, 2016, to June 25, 2016, is considered which encompasses a magnetic storm of moderate size recorded at the Brandon, Manitoba and Fredericksburg, Virginia magnetic observatories over 3 days. Two impedance sites were chosen in each case which represent different responses while being within close geographic proximity and within the same physiographic zone. This study produces estimated time series of the geoelectric field throughout the duration of a magnetic storm, providing an understanding of how the geoelectric field differs across small geographic distances within the same physiographic zone. This study shows that the geoelectric response of two sites within $200 \mathrm{~km}$ of one another can differ by up to two orders of magnitude $(4484 \mathrm{mV} / \mathrm{km}$ at one site and $41 \mathrm{mV} / \mathrm{km}$ at another site $125 \mathrm{~km}$ away). This study demonstrates that the application of uniform 1-dimensional conductivity models of the subsurface to wide geographic regions is insufficient to predict the geoelectric hazard at a given site. This necessitates that an evaluation of the 3-dimensional conductivity distribution at a given location is necessary to produce a reliable estimation of how the geoelectric field evolves over the course of a magnetic storm.
\end{abstract}

\section{Introduction}

Geomagnetic storms interact with power systems through geoelectric currents induced in the Earth's electrically conducting interior (e.g., Pirjola 2002; Molinski 2002). These storms represent a hazard to power transmission infrastructure through their potential to interfere with operations and result in damage to transformers and other critical components. Infrastructure damage due to magnetic storms has occurred on numerous occasions, such as the March 1989 storm that caused blackouts in the Hydro-Quebec power grid of Canada (e.g., Allen et al. 1989; Béland and Small 2005) as well as power failures from the August 1972 storm (e.g., Anderson et al.

\footnotetext{
*Correspondence: scuttler@mymail.mines.edu

1 Department of Geophysics, Colorado School of Mines, 1500 Illinois St, Golden, CO 80401, USA

Full list of author information is available at the end of the article
}

1974). Interest in averting the deleterious effects of magnetic storms has motivated regulatory agencies to issue instructions to power grid companies to assess the resilience of their operations and infrastructure in preparation for future magnetic storms (FERC 2013) (Order No. 77) (e.g., Veeramany et al. 2016), academic work on magnetic storm assessment (e.g., Schrijver et al. 2015), and risk assessments in the private sector (e.g., Riswadkar and Dobbins 2010; AonBenfield 2013; Lloyds 2013).

In order to prepare for a magnetic storm, those who maintain power systems need the induced geoelectric field in a given geographic region. Local assessments of geoelectric field estimation have been performed at various places around the world (e.g., Boteler 2001; Viljanen et al. 2013; Torta et al. 2014). In addition to direct monitoring of the geoelectric field, one can estimate the geoelectric field though characterizing and mapping the behavior of the Earth's ground-level geomagnetic field 
across broad geographic regions (e.g., Love et al. 2016) and characterizing an impedance (e.g., Chave 2012) at a given location, which is dependent on the 3-dimensional conductivity distribution of the Earth's interior (e.g., Bedrosian and Feucht 2014; Meqbel et al. 2014; Alekseev et al. 2015). Subsurface conductivity can also be characterized with active sources, as described in works such as Spies and Frischknecht (1991) on land or Swidinsky et al. (2015) in the marine environment; such conductivity models can be used to supplement impedances typically constructed using passive magnetotelluric methods.

Geoelectric mapping studies incorporate impedance tensors derived from magnetotelluric measurements of the geomagnetic and geoelectric fields (e.g., Egbert 2007) such as those collected from the USArray program (e.g., Schultz 2009; Williams et al. 2010 ). These include Bedrosian and Love (2015), who use 3-dimensional magnetotelluric EarthScope impedances to estimate the geoelectric response of a simulated time-varying geomagnetic field across northern North America. Love et al. (2016a) used these impedances to produce a hazard map of half of the USA by convolving these impedances against latitudedependent maps of extreme geomagnetic activity. Torta et al. (2017) improved the estimate of the phase and magnitude of measured geomagnetically induced currents (GICs) in power transmission systems by modeling local 2- and 3-dimensional conductivity structures with their impedances.

Recognizing that many ongoing efforts to estimate geoelectric hazards utilize conductivity models representing broad physiographic regions through 1-dimensional conductivity models, there is a need to improve estimations of the geoelectric hazards as discussed in the U.S. Space Weather Action Plan (NSTC 2015). We investigate how an estimation of the geoelectric field can differ between two closely spaced sites within the same physiographic region in order to highlight the importance of using accurate Earth impedance tensors.

\section{Induction}

We are concerned with the relationship between a ground-level geomagnetic field $\mathbf{B}(t, x, y)$ generated as a result of magnetic storm activity and the induced geoelectric field variations $\mathbf{E}(t, x, y)$ at a given location $(x, y)$ on the Earth as a function of time $t$. We consider the inducing geomagnetic field $\mathbf{B}(t, x, y)$ to be a locally planar field, with time-varying horizontal geomagnetic fields $\left(B_{x}, B_{y}\right)$ and geoelectric fields $\left(E_{x}, E_{y}\right)$ (e.g., Cagniard 1953). In addition, we are interested in the frequency band that produces the greatest hazard risk of power systems: $10^{-1}$ $-10^{-4} \mathrm{~Hz}$ (periods of $10-10,000 \mathrm{~s}$ ) (Barnes et al. 1991; NERC 2014a, b). This range allows us to invoke the quasi-static approximation, thus electromagnetic induction in the Earth becomes a diffusive process that ignores displacement currents.

The Fourier transform relates our geomagnetic and geoelectric fields in time to the frequency domain according to

$$
\mathcal{F} \mathbf{B}(t)=\tilde{\mathbf{B}}(f) \quad \text { and } \quad \mathcal{F} \mathbf{E}(t)=\tilde{\mathbf{E}}(f),
$$

where $f$ is the frequency of sinusoidal variation. In magnetotellurics, one uses $\tilde{\mathbf{B}}(f, x, y)$ and $\tilde{\mathbf{E}}(f, x, y)$ to determine a complex impedance tensor $\overline{\overline{\mathbf{Z}}}(f, x, y \mid \sigma(\mathbf{r}))$ having units of ohms $(\Omega)$, where $\sigma(\mathbf{r})$ is the subsurface conductivity distribution, and $\mathbf{r}$ is a position vector (Weidelt and Chave 2012, chapter 4.1.2). The impedance tensor can be written as

$$
\overline{\overline{\mathbf{Z}}}(f, x, y \mid \sigma(\mathbf{r}))=\left[\begin{array}{ll}
Z_{x x} & Z_{x y} \\
Z_{y x} & Z_{y y}
\end{array}\right](f, x, y \mid \sigma(\mathbf{r})),
$$

and is the result of induction within the 3-dimensional conductivity distribution of the subsurface which corresponds to the geology of the volume of Earth at a given geographic location $(x, y)$. In this 3-dimensional case, each element of the tensor $\left(Z_{x x}, Z_{x y}, Z_{y x}\right.$, and $\left.Z_{y y}\right)$ is nonzero and independent of other components, and the subscripts $(x, y)$ correspond to the northing and easting of the geographic location, respectively. The impedance tensor is related to the geomagnetic field $\tilde{\mathbf{B}}(f, x, y)$ and the geoelectric field $\tilde{\mathbf{E}}(f, x, y)$ via

$$
\tilde{\mathbf{E}}(f, x, y)=\frac{1}{\mu} \overline{\overline{\mathbf{Z}}}(f, x, y \mid \sigma(\mathbf{r})) \cdot \tilde{\mathbf{B}}(f, x, y),
$$

where $\mu$ is magnetic permeability. Equation 3 can be used to estimate the geoelectric field in the frequency domain at a given location.

\section{Data}

The USArray EarthScope program supported by the National Science Foundation (NSF) consists of a continent-wide survey of seismic and magnetotelluric sites conducted throughout the USA since 2006. This study considers a collection of impedances at discrete geographic locations. $1 \mathrm{~Hz}$ geomagnetic vector field data were collected via fluxgate magnetometers, and $1 \mathrm{~Hz}$ geoelectric field data were collected via pairs of lead-lead chloride nonpolarizing electrodes arranged in a standard magnetotelluric array (Schultz 2010). We selected four sites for comparison in this study, two sites each within two physiographic zones PT-1 and SU-1 (Fig. 1). Each impedance was derived from a measured geoelectric and geomagnetic time series at 30 discrete periods from $T=7.3143$ to $T=1.8725 \cdot 10^{4} \mathrm{~s}$ (Egbert 2007).

We consider two impedances located $125 \mathrm{~km}$ apart in Minnesota, USA: RED36 (Fig. 2) and MNB36 (Fig. 3), 

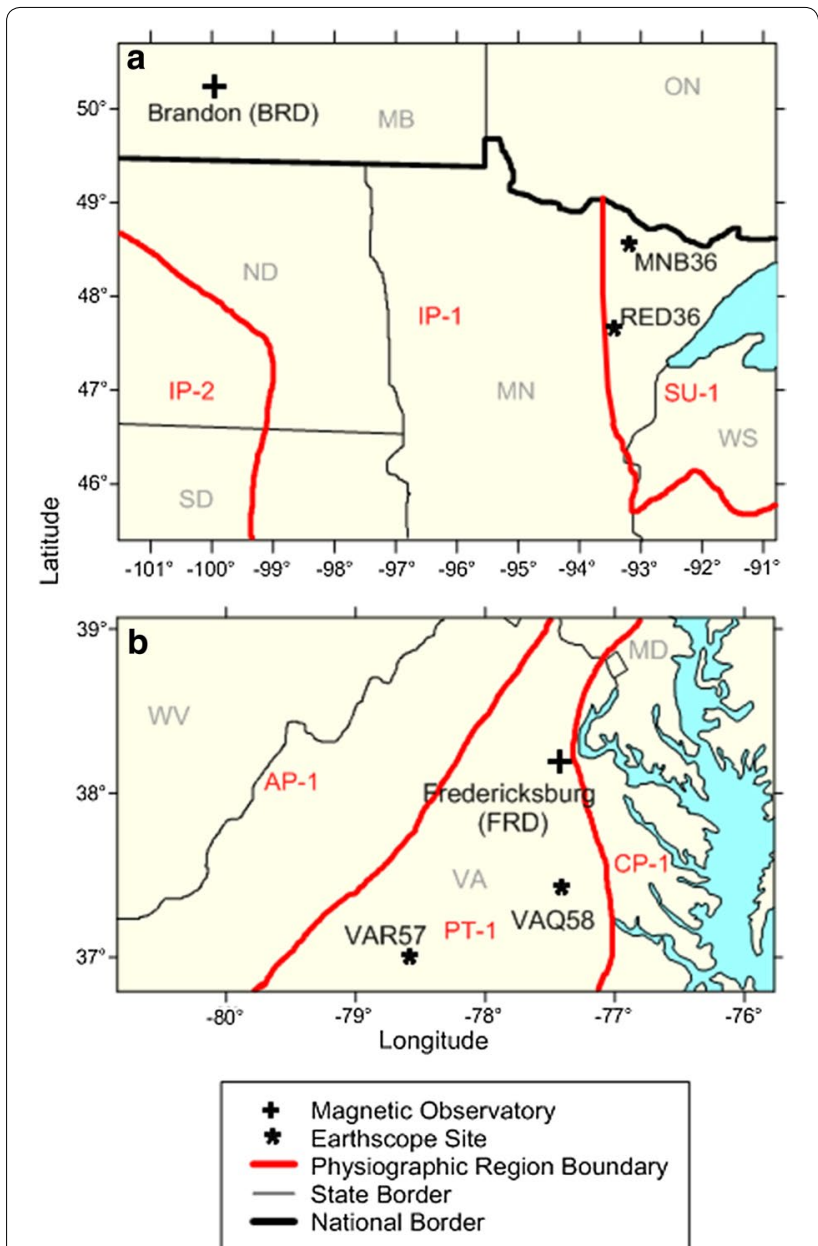

Fig. 1 Maps showing the locations of the magnetic observatories (available through the INTERMAGNET program) and the EarthScope USArray survey sites referenced to physiographic zones in red [derived from Fernberg (2012)]. a The NRC Brandon (BRD) magnetic observatory in Manitoba and the EarthScope sites MNB36 and RED36 in northern Minnesota. Both sites fall within the SU-1 physiographic zone. b The USGS Fredericksburg (FRD) magnetic observatory in Virginia and the EarthScope sites VAR57 and VAQ58 in southern and eastern Virginia, which fall within the PT-1 zone

with MNB36 almost directly north of RED36. The geologic setting in this area is controlled by a mid-continent rift system, which produced a series of intracontinental sedimentary basins juxtaposed against older cratonic rock. These juxtapositions are further exaggerated by faulting that places conductive, sedimentary rock characteristic of basin fill against more resistive igneous and metamorphic cratonic rock (Bally and Palmer 1989). MNB36 is located within the Archean Superior province to the north while RED36 is located within the Animikie Basin to the south. We also considered two impedances located $200 \mathrm{~km}$ apart in Virginia, USA: VAR57 and
VAQ58, with VAR57 $100 \mathrm{~km}$ west-southwest of VAQ58. Both VAR57 and VAQ58 are in the Piedmont province of the southern Appalachian Mountains, which is mainly composed of accreted sedimentary material thrust upon the North American plate.

Figure 2 shows the impedance for RED36 which, as we shall see corresponds to smaller estimations of $E(x, y, t)$. Here, the real components of the complex impedance tensor are represented in blue while imaginary components are represented in red. Figure $2 \mathrm{a}-\mathrm{d}$ corresponds to the $Z_{x x}, Z_{x y}, Z_{y x}$, and $Z_{y y}$ components of the impedance tensor, respectively. Figure 3 represents the impedance for MNB36 similarly, which corresponds to the larger geoelectric response (note the difference in $y$ scale compared to Fig. 4). In Fig. 2, we see that the diagonal components of the impedance response $\left(Z_{x x}\right.$ and $\left.Z_{y y}\right)$ are very small, indicating that the conductivity distribution of the subsurface is close to 1-dimensional. The off-diagonal components $\left(Z_{x y}\right.$ and $\left.Z_{y x}\right)$, though unique from one another, only reach $2 \Omega$ in each component at shorter periods. Comparing Figs. 2 to 3, MNB36 demonstrates a much stronger transfer function compared with RED36. The plots for MNB36 further show a much larger difference in $Z_{x x}$ and $Z_{y y}$, indicating that the subsurface conductivity distribution is more representative of a 3-dimensional conductivity model.

Discrete time series of the near-surface geomagnetic field (Love and Chulliat 2013) were obtained through the Brandon (BRD) Magnetic Observatory located in Brandon, Manitoba, operated by National Resources Canada (NRCan), and the Fredericksburg (FRD) Geomagnetic Observatory in Fredericksburg, Virginia, operated by the U.S. Geologic Survey (USGS). These observatories were considered due to their proximity to the EarthScope impedance tensors (Fig. 1). The geomagnetic data gathered at these observatories have a sensitivity of 0.1 $\mathrm{nT}$ and have undergone digital and analog filtering. The magnetic storm we selected for this study occurred on June 22, 2015, and was recorded at both observatories at a sampling frequency of $1 \mathrm{~Hz}$ over 3 days beginning at 00:00 on June 22, 2015. This time interval encompasses the magnetic storm from its onset at approximately 18:00 on June 22,2015 , to its cessation at approximately 20:00 on June 25, 2015.

Figure 4a shows the geomagnetic field measured during the June 22, 2016, storm at BRD and the corresponding estimations of the geoelectric field calculated via Eq. 3. In Fig. $4 \mathrm{a}, B_{x}(t)$ is represented in black and $B_{y}(t)$ in green. This geomagnetic times series incorporates the entire evolution of the geomagnetic storm over the course of three full days beginning at 00:00 of June 22, 2016. The storm reaches its largest magnitude of $1207 \mathrm{nT}$ in $B_{x}(t)$ and $725 \mathrm{nT}$ in $B_{y}(t)$ during the first day of the storm, with 

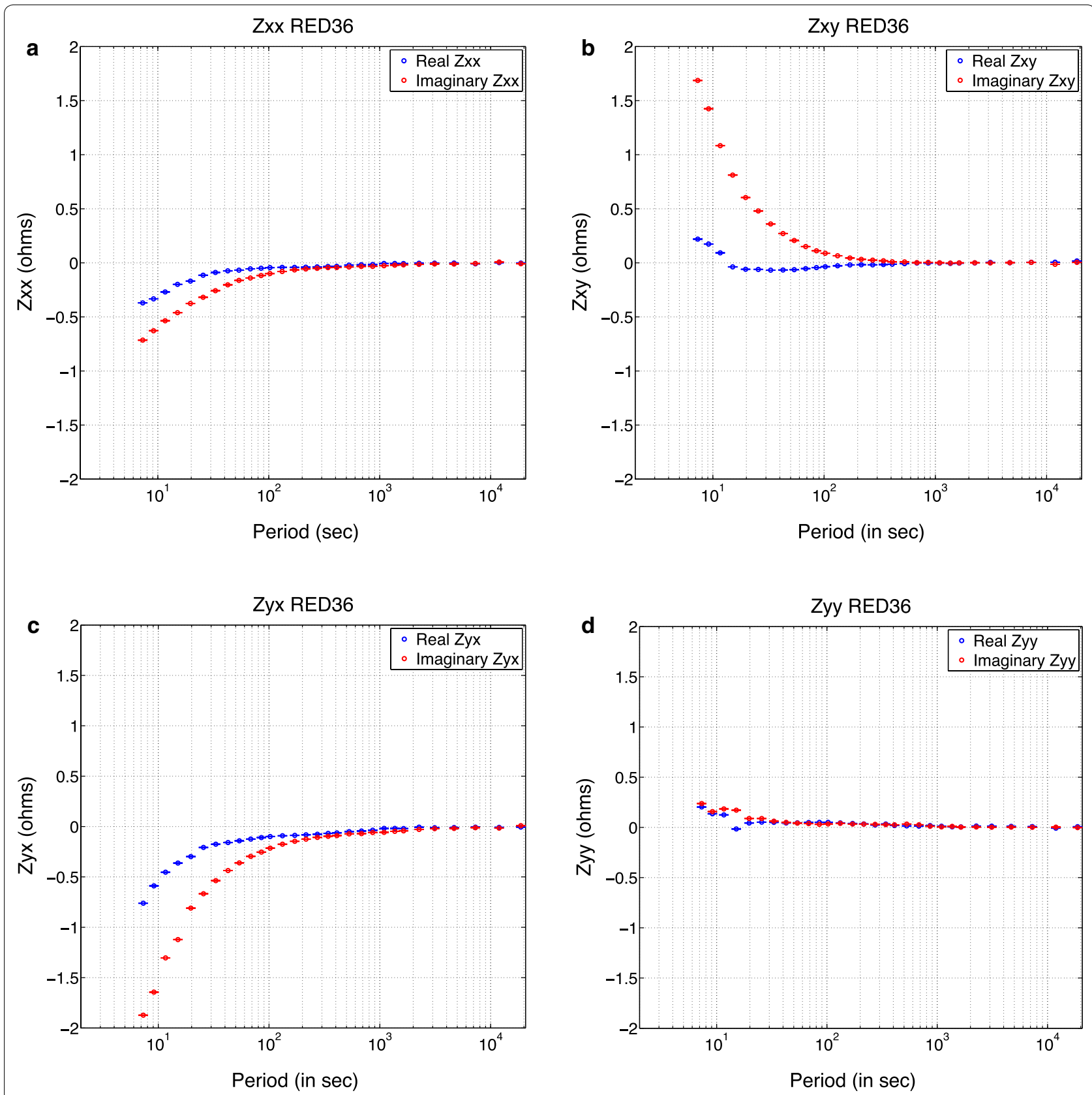

Fig. 2 Real (blue) and imaginary (red) impedance plots from the EarthScope survey site RED36, which were used to produce estimations of the geoelectric field with the Brandon (BRD) observatory geomagnetic time series

the largest geomagnetic variation occurring between 18:00 on June 22, 2016, to 12:00 on June 23, 2016. After 18:00 on June 24, 2016, geomagnetic activity concludes and the geomagnetic field returns to a baseline value. Figure 5 a shows the geomagnetic field measured during the June 22, 2016, storm at FRD. Though we show the same June 22, 2016, magnetic storm over the same time interval, the response of $B_{x}(t)$ and $B_{y}(t)$ measured at FRD is smaller in magnitude, reaching $213 \mathrm{nT}$ in $B_{x}(t)$ and 150 $\mathrm{nT}$ in $B_{y}(t)$ during the first day of the storm. As with $B R D$, the largest geomagnetic variations occur between 18:00 on June 22,2015 , and 12:00 on June 23,2015 . The magnitude of the geomagnetic field at the Virginia sites is reduced compared to the Minnesota sites, likely due to the difference in latitude between the two magnetic observatories: BRD is located within the auroral oval 

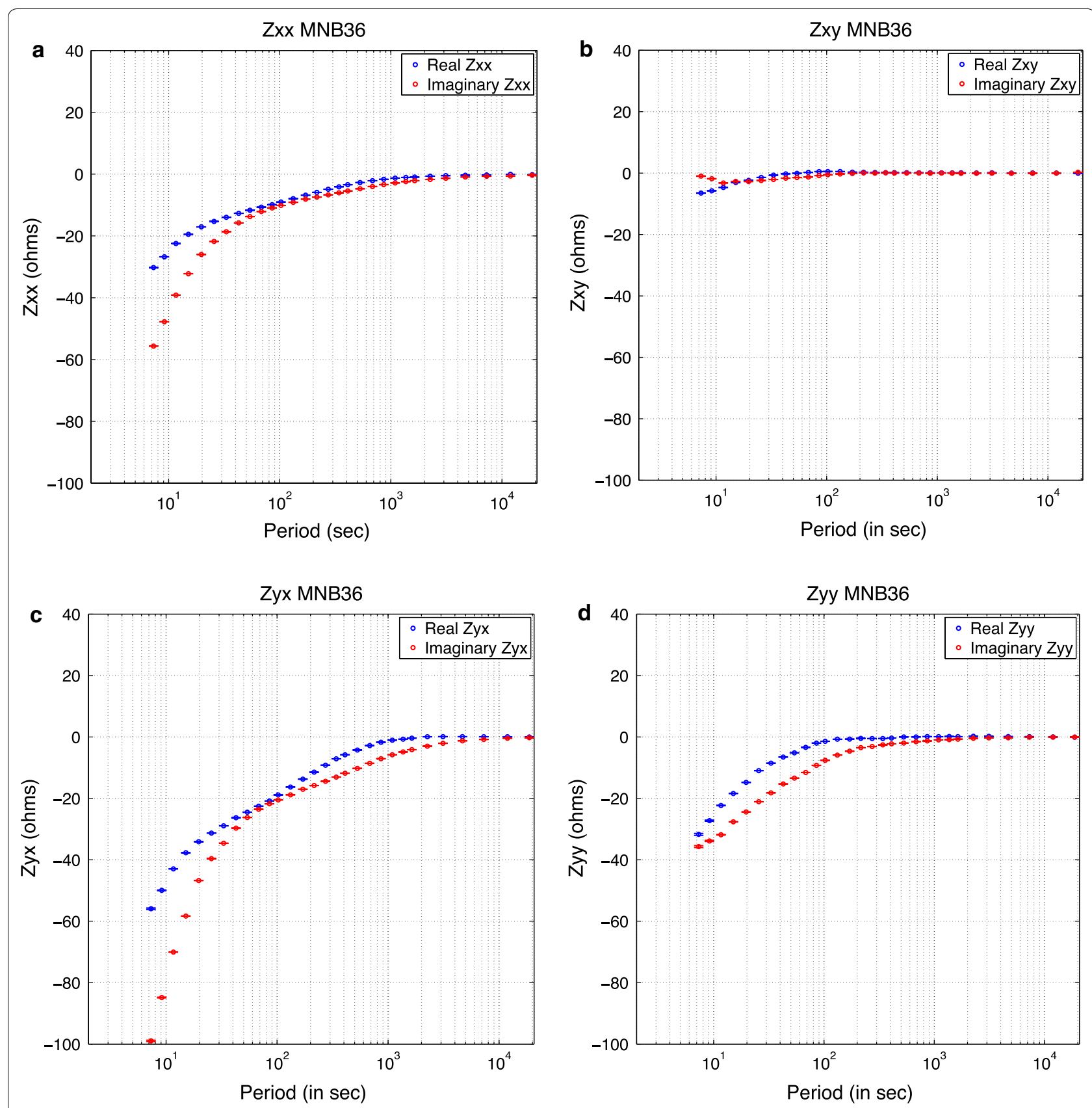

Fig. 3 Real (blue) and imaginary (red) impedance plots from the EarthScope survey site MNB36, which were used to produce estimations of the geoelectric field with the Brandon (BRD) observatory geomagnetic time series

at $49.8^{\circ}$ latitude $\left(50^{\circ}\right.$ magnetic latitude), while FRD is located below the auroral oval at $38.2^{\circ}$ latitude $\left(40^{\circ} \mathrm{mag}\right.$ netic latitude).

\section{1-D conductivity models and physiographic zones}

Fernberg (2012) characterizes several physiographic zones within the continental USA by a 1-dimensional conductivity model of the subsurface for geomagnetic hazard assessment. RED36 and MNB36 in Minnesota fall within the physiographic zone described by the 1-D conductivity model SU-1 or the Superior Uplands that characterize Minnesota, Wisconsin, and Upper Michigan, which is characterized by $10 \mathrm{~km}$ of resistive (approximately $7000 \Omega \mathrm{m}$ ) upper crust and decreasing resistivities approaching the upper mantle. VAR57 and VAQ58 fall within the physiographic zone described by 


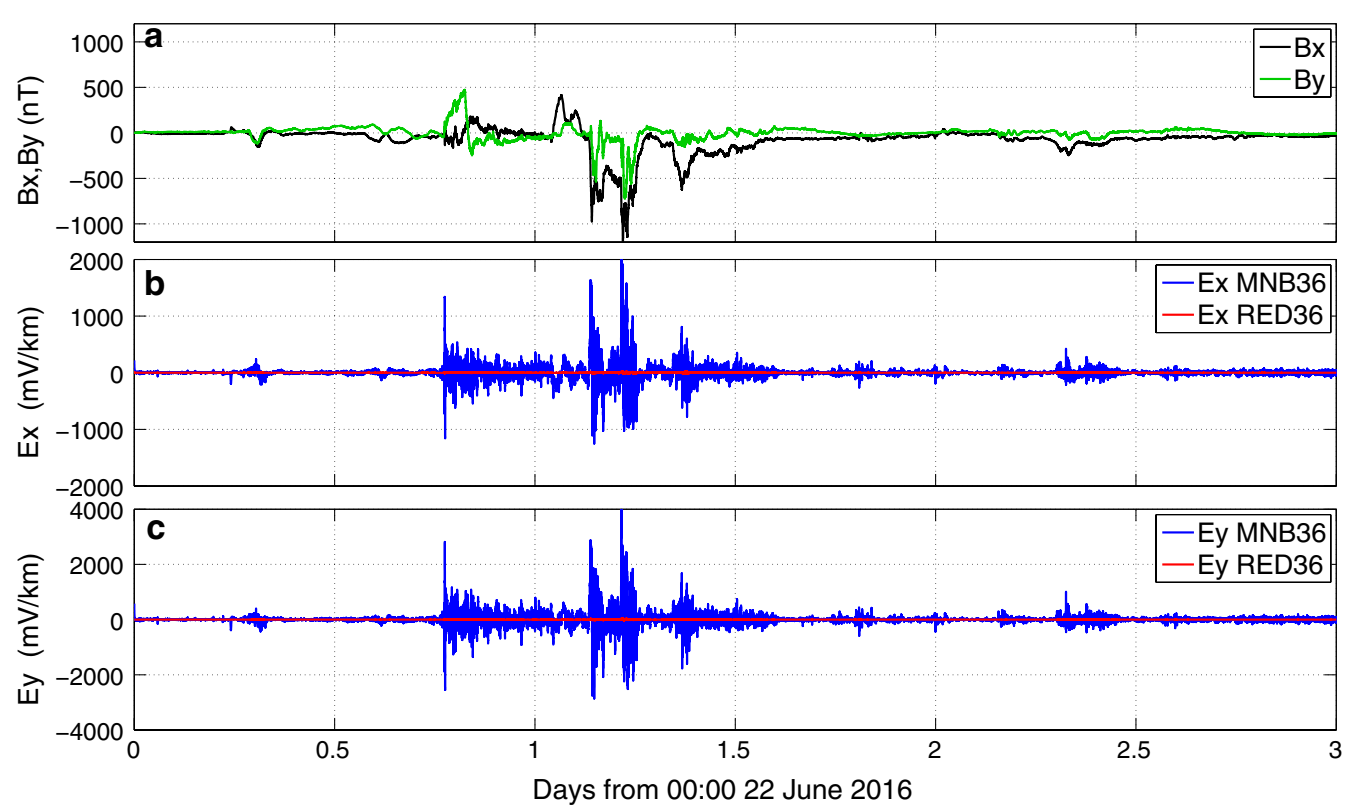

Fig. 4 Time series for geomagnetic fields at the Brandon (BRD) Magnetic Observatory for the June 22, 2016, storm for 3 days beginning at 00:00 June 22,2016 , and corresponding estimated geoelectric fields. a $1 \mathrm{~s}$ resolution geomagnetic field $B_{x}(t)\left(\right.$ black) and $B_{y}(t)($ green) in $\mathrm{nT}$ defined relative to a constant baseline, $\mathbf{b}$ estimations of the geoelectric field $E_{x}$ for EarthScope impedance MNB36 (blue) and RED36 (red) in mV/km, c equivalent time series to (b) for estimated $E_{y}$

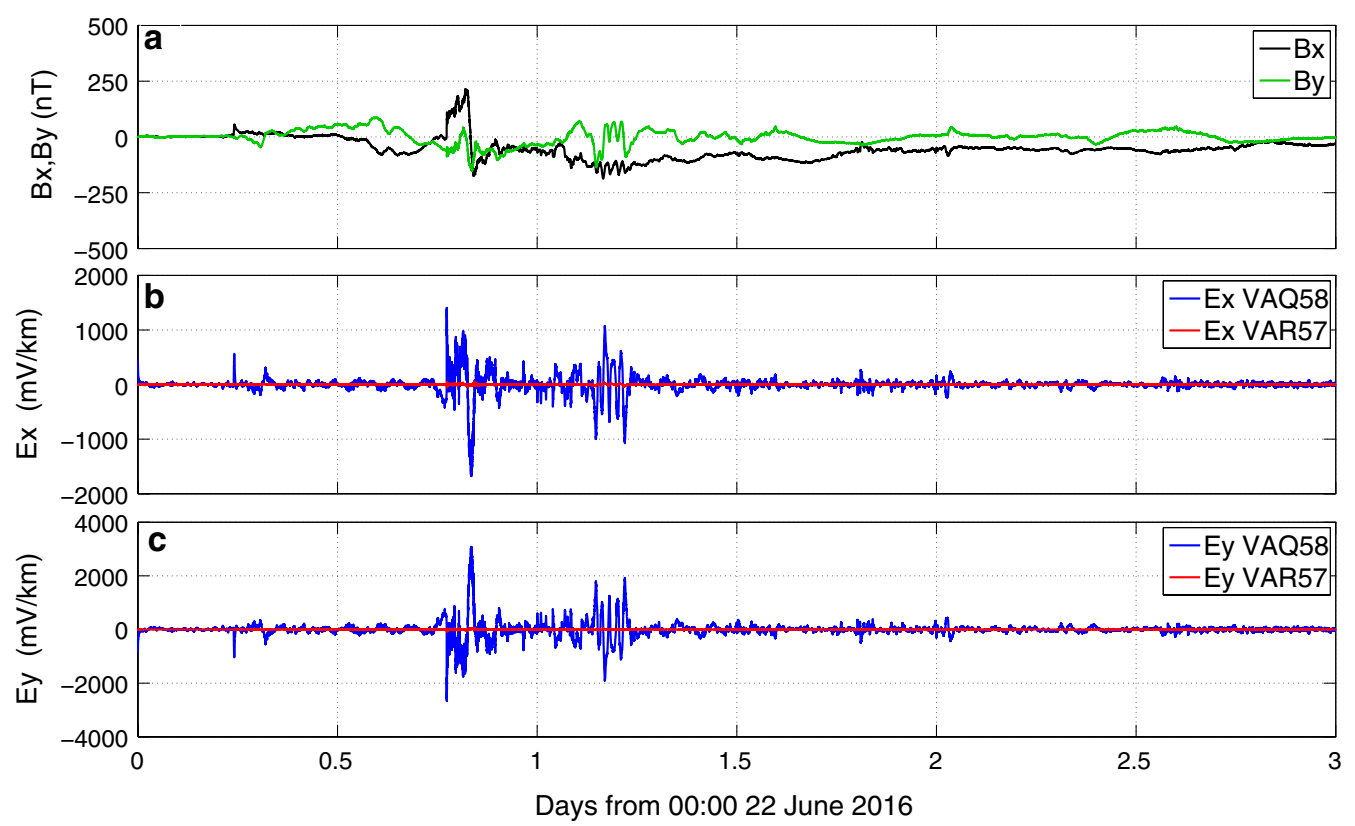

Fig. 5 Time series for geomagnetic fields at the Fredericksburg (FRD) Magnetic Observatory for the June 22, 2016, storm for 3 days beginning at 00:00 June 22, 2016, and corresponding estimated geoelectric fields. a 1 s resolution geomagnetic field $B_{x}(t)(\mathrm{black})$ and $B_{y}(t)$ (green) in nT defined relative to a constant baseline, $\mathbf{b}$ estimations of the geoelectric field $E_{x}$ for EarthScope impedance VAQ58 (blue) and VAR57 (red) in mV/km, c equivalent time series to $(\mathbf{b})$ for the estimated $E_{y}$ 
the conductivity model PT- 1 in eastern Virginia. PT- 1 is characterized by low resistivity $(100 \Omega \mathrm{m})$ sedimentary basin for the first $10 \mathrm{~km}$ depth, and then decreasing in resistivity approaching the upper crust. These 1-dimensional conductivity models encompass large geographic regions of the USA which demonstrate considerable geologic complexity. Bedrosian and Love (2015) have demonstrated that such broad applications of these models to geologically complex regions do not remain consistent when evaluated against EarthScope impedances. These models do not consider the 3-dimensional effects of geoelectric induction when estimating the geoelectric field.

\section{Methods}

Because we use a measured geomagnetic field in the time domain yet derive magnetotelluric impedances in the frequency domain, we apply a discrete Fourier transform (e.g., Press et al. 1992) to the geomagnetic time series in order to compare directly the two according to Eq. 3. Our impedances $\overline{\mathbf{Z}}(f, x, y \mid \sigma(\mathbf{r}))$ are defined according to Eq. 2 and are interpolated using a cubic spline over the equivalent frequency band. In order to minimize the influence of extrapolated $\overline{\overline{\mathbf{Z}}}(f, x, y \mid \sigma(\mathbf{r}))$ beyond the frequency band where data are present, a band-pass Butterworth filter is applied. We chose cutoff frequencies to be $10^{-1} \mathrm{~Hz}$ (an equivalent period $T$ of $10 \mathrm{~s}$ ) and $10^{-4} \mathrm{~Hz}$ (an equivalent period $T$ of 10,000 s) because electrical power grids are primarily susceptible to varying geoelectric fields between periods of 10 to $10,000 \mathrm{~s}$ (Barnes et al. 1991; NERC 2014a, b) and because the impedances are limited to this frequency band. After applying Eq. 3 to the geomagnetic data and the filtered impedances, we apply an inverse Fourier transform to produce an estimation of the geoelectric field as a function of time over the duration of the magnetic storm. This method is then verified against data collected through the USArray EarthScope program, specifically site MNB36 where measured data were collected during the June 22,2015 , storm, in order to ensure that our estimated results are in agreement with geoelectric fields measured at the same time and location that the geomagnetic time series was collected. This assessment yielded an RMS percent error for $E_{x}$ of 39.26 and for $E_{y}$ of 17.93 and maximum values of measured $E_{x}$ to be $191 \mathrm{mV} / \mathrm{km}$ and estimated $E_{x}$ to be $199 \mathrm{mV} / \mathrm{km}$, while for measured $E_{y}$ to be $338 \mathrm{mV} / \mathrm{km}$ and estimated $E_{y}$ to be $383 \mathrm{mV} / \mathrm{km}$ for the MNB36 site.

\section{Results}

Figure $4 \mathrm{~b}$, c shows the geoelectric response in time associated with the same geomagnetic time series for the June 22, 2016, storm for $E_{x}(t)$ and $E_{y}(t)$, respectively. Each panel demonstrates the important effect on the induced geoelectric field of solid-Earth impedance. Despite being only $125 \mathrm{~km}$ apart, the geoelectric response for MNB36 is several orders of magnitude higher than the geoelectric response of RED36, particularly in $E_{y}$. In $E_{x}$, the maximum magnitude reached for MNB36 is $2275 \mathrm{mV} /$ $\mathrm{km}$, while RED36 only reaches a maximum magnitude of $29 \mathrm{mV} / \mathrm{km}$. In $E_{y}$, this difference in magnitude is much larger, with the geoelectric response of MNB36 reaching a maximum magnitude of $4484 \mathrm{mV} / \mathrm{km}$ while RED36 only reaches a maximum magnitude of $41 \mathrm{mV} / \mathrm{km}$.

As with the geomagnetic field, the largest geoelectric variation occurs between the onset of the storm at approximately 0.75 days into the time series and concludes shortly after 1.5 days, with the maximum magnitudes occurring within this period. Some smaller induced geoelectric fields occur afterward, but these responses are an order of magnitude smaller than during the initial storm period, with $E_{y}$ of MNB36 reaching a maximum magnitude of $400 \mathrm{mV} / \mathrm{km}$ during these periods. We note that $E_{y}$ is on average twice the magnitude of $E_{x}$ for both survey sites. This is related to the response of $E_{y}$ being coupled to the inducing geomagnetic field $B_{x}$; a large $B_{x}$ produces a correspondingly large response in $E_{y}$.

In Fig. 5, we show similar estimations of the geoelectric fields at two sites in the state of Virginia, which are also considered to be in the same physiographic zone according to Fernberg (2012). Specifically, Fig. 5b, c shows the geoelectric response in time associated with the June 22, 2016, storm for $E_{x}(t)$ and $E_{y}(t)$, respectively. Each plot shows the effect of two impedances: EarthScope USArray VAQ58 in blue and VAR57 in red. These two sites are farther apart at a distance of $200 \mathrm{~km}$ and located within different physiographic zones. As with the Minnesota example, the geoelectric response for VAQ58 is several orders of magnitude higher than the geoelectric response of VAR57, particularly in $E_{y}$. In $E_{x}$, the maximum magnitude reached for VAQ58 is $1402 \mathrm{mV} / \mathrm{km}$, while VAR57 only reaches a maximum magnitude of $93 \mathrm{mV} / \mathrm{km}$. In $E_{y}$, this difference in magnitude is much more drastic, with the geoelectric response of VAQ58 reaching a maximum magnitude of $3862 \mathrm{mV} / \mathrm{km}$ while VAR57 only reaches $148 \mathrm{mV} / \mathrm{km}$.

\section{Implications for geohazard assessment}

Our results show that geoelectric fields within the same physiographic region can be several orders of magnitude different even during the same magnetic storm. This implies that, in general, when estimating geoelectric fields during a magnetic storm, one cannot expect a simple 1D model of the conductivity distribution of the subsurface to apply to a wider physiographic region. In both regions considered here (Minnesota and Virginia), we estimated the maximum geoelectric field at two sites to be two orders of magnitude different despite being 
located in the same physiographic zones and proximal to one another. While Bedrosian and Love (2015) used a simple sinusoidal source, we have shown a similar result derived from observatory geomagnetic fields. Therefore, by considering the measured impedance at each site rather than applying a 1-dimensional conductivity model to a wide region, we can improve estimates of the behavior and amplitude of the geoelectric field and the corresponding risk to electric power grids.

The data demonstrate that sites with complex, 3-dimensional distributions in the subsurface are associated with responses in the estimated geoelectric time series, but other variables are present that may also have significant influence. Some of these variables include the latitude of the site with respect to the auroral oval and the development of the magnetic storm itself with time. Future study will need to examine the geoelectric response associated with sharp lateral conductivity gradients, such as those at the ocean-land interface (Torta et al. 2017). Such factors will require further study to determine how each specifically influences estimates of the behavior of the geoelectric field at a given location.

\section{Authors' contributions}

SWC carried out the development and implementation of the algorithm, JJL helped develop the algorithm, provided the datasets used in this publication and reviewed the manuscript for critical content, and AS helped develop the algorithm and reviewed the manuscript for critical content. All authors read and approved the final manuscript.

\section{Author details}

${ }^{1}$ Department of Geophysics, Colorado School of Mines, 1500 Illinois St, Golden, CO 80401, USA. ${ }^{2}$ Geomagnetism Program USGS, United States Geologic Survey, DFC Box 25046, MS 966, Denver, CO 80225-0046, USA.

\section{Acknowlegements}

We gratefully acknowledge the support provided by the National Science Foundation (NSF) under Award Number 15-20864. We thank C. A. Finn, G. M. Lucas, J. McCarthy, J. Slate and two anonymous referees for reading a draft manuscript. We thank A. Kelbert for useful conversations. The results presented in this paper rely on data collected at magnetic observatories. We thank the national institutes that support them and INTERMAGNET for promoting high standards of five magnetic observatory practice (www. intermagnet.org). USArray MT TA project was led by PI Adam Schultz and Gary Egbert. They would like to thank the Oregon State University MT team and their contractors, lab and field personnel over the years for assistance with data collection, quality control, processing and archiving. We also thank numerous districts of the U.S. Forest Service, Bureau of Land Management, the U.S. National Parks, the collected State land offices, and the many private landowners who permitted access to acquire the MT TA data. USArray TA was funded through NSF Grants EAR-0323311, IRIS Subaward 478 and 489 under NSF Cooperative Agreement EAR-0350030 and EAR-0323309, IRIS Subaward 75-MT under NSF Cooperative Agreement EAR-0733069 under CFDA No. 47.050, and IRIS Subaward 05-OSU-SAGE under NSF Cooperative Agreement EAR-1261681.

\section{Competing interests}

The authors declare that there are no competing interests.

\section{Ethics approval and consent to participate}

Not applicable.

\section{Publisher's Note}

Springer Nature remains neutral with regard to jurisdictional claims in published maps and institutional affiliations.

Received: 4 August 2017 Accepted: 20 February 2018

Published online: 08 March 2018

\section{References}

Alekseev D, Kuvshinov A, Palshin N (2015) Compilation of 3-D global conductivity model of the Earth for space weather applications. Earth Planets Space 67:1-11. https://doi.org/10.1186/s40623-015-0272-5

Allen J, Frank L, Sauer H, Reiff P (1989) Effects of the March 1989 solar activity. Eos Trans AGU 70(46):1479, 1486-1488

Anderson CW, Lanzerotti LJ, MacLennan G (1974) Outage of the L4 system and the geomagnetic disturbances of 4 August 1972. Bell Syst Tech J 53(9):1817-1837

Aon Benfield (2013) Geomagnetic storms. Aon Benfield, Sydney, pp 1-12

Bally AW, Palmer AR (1989) The geology of North America: an overview. Geological Society of America. Boulder, Colo, pp 1-629. https://doi. org/10.1130/DNAG-GNA-A

Barnes PR, Rizy DT, McConnell BW, Tesche FM, Taylor ER, Jr (1991) Outage of the L4 system and the geomagnetic disturbances of 4 August 1972. In: Electric utility industry experience with geomagnetic disturbances, vol ORNL 6665. Oak Ridge Natl. Lab, pp 1-78

Bedrosian PA, Feucht DW (2014) Structure and tectonics of the northwestern United States from EarthScope USArray magnetotelluric data. Earth Planet. Sci. Lett. 402:275-289. https://doi.org/10.1016/j.epsl.2013.07.035

Bedrosian PA, Love JJ (2015) Mapping geoelectric fields during magnetic storms: synthetic analysis of empirical United States impedances. Geophys. Res. Lett. 42(23):10160-10170

Béland J, Small K (2005) Space weather effects on power transmission systems: the cases of Hydro-Québec and Transpower NewZealandLtd. In: Daglis IA (ed) Effects of space weather on technology infrastructure. Springer, Dordrecht

Boteler DH (2001) Assessment of geomagnetic hazard to power systems in Canada. Nat. Hazards 23:101-120

Cagniard L (1953) Basic theory of the magneto-telluric method of geophysical prospecting. Geophysics 18(3):605-635

Chave AD (2012) Estimation of the magnetotelluric response function. In A. Chave \& A. Jones (Eds.), The Magnetotelluric Method: Theory and Practice (p. lii). Cambridge: Cambridge University Press.

Egbert GD (2007) Robust electromagnetic transfer functions estimates. In: Gubbins D, Herrero-Bervera E (eds) Encyclopedia of geomagnetism and paleomagnetism. Springer, Dordrecht, pp 866-870

FERC (2013) Reliability standards for geomagnetic disturbances. Federal Energy Regulatory Commission Federal Regulatory Rules Regulations 78(100):30747-30762

Fernberg P (2012) One-dimensional earth resistivity models for selected areas of continental United States and Alaska. EPRI Technical Update 1026430, pp 1-190

Lloyds (2013) Emerging risk report: solar storm risk to the North American electric grid. Lloyds, London, pp 1-22

Love JJ, Chulliat A (2013) An international network of magnetic observatories. Eos Trans AGU 94(42):373-384. https://doi. org/10.1002/2013EO420001

Love J, Pulkkinen A, Bedrosian PA, Jonas S, Kelbert A, Rigler EJ, Finn CA, Balch CC, Rutledge R, Waggel R, Sabata AT, Kozyra JU, Black CE (2016a) Geoelectric hazard maps for the continental United States. Geophys. Res. Lett. 43:1-10. https://doi.org/10.1002/2016GL070469

Love JJ, Coïsson P, Pulkkinen A (2016b) Global statistical maps of extremeevent magnetic observatory 1 min first differences in horizontal intensity. Geophys. Res. Lett. 43:4126-4135. https://doi.org/10.1002/2016GL068664

Meqbel NM, Egbert GD, Wannamaker PE, Kelbert A, Schultz A (2014) Deep electrical resistivity structure of the northwestern U.S. derived from 3-D inversion of USArray magnetotelluric data. Earth Planet. Sci. Lett. 402:290304. https://doi.org/10.1016/j.epsl.2013.12.026 
Molinski TS (2002) Why utilities respect geomagnetically induced currents. J. Atmos. Solar. Terr. Phys. 64:1765-1778

NERC (2014a) Benchmark geomagnetic disturbance event description. North American Electric Reliability Corporation (NERC), Atlanta, pp 1-26

NERC (2014b) Transformer thermal impact assessment: project 2013-03 (geomagnetic disturbance mitigation). North American Electric Reliability Corporation (NERC), Atlanta, pp 1-16

NSTC (2015) National space weather action plan. National Science and Technology Council (U.S.) United States. Executive Office of the President, pp 1-12

Pirjola R (2002) Review on the calculation of surface electric and magnetic fields and of geomagnetically induced currents in ground-based technological systems. Surv. Geophys. 23:71-90

Press W, Teukolsky S, Vetterling W, Flannery B (1992) Numerical recipes in Fortran 77 the art of scientific computing, 2nd edn. Cambridge University Press, New York City

Riswadkar AV, Dobbins B (2010) Solar storms: protecting your operations against the sun dark side. Zurich Services Corp, pp 1-12. https://doi. org/10.1029/2004SW000123

Schrijver C, Kauristie K, Aylward A, Denardini C, Gibson S, Glover A, Gopalswamy N, Grande M, Hapgood M, Heynderickx D, Jakowski N, Kalegaev V, Lapenta G, Linker J, Liu S, Mandrini C, Mann I, Nagatsuma T, Nandy D, Obara T, O'Brien T, Onsager T, Opgenoorth H, Terkildsen M, Valladares C, Vilmer N (2015) Understanding space weather to shield society: a global road map for 2015 to 2025 commissioned by COSPAR and ILWS. AdV. Space Res. 55(12):2745-2807. https://doi.org/10.1016/j.asr.2015.03.023

Schultz A (2009) EMScope: a continental scale magnetotelluric observatory and data discovery resource. Data. Sci. J. 8:IGY6-IGY20

Schultz A (2010) A continental scale magnetotelluric observatory and data discovery resource. Data. Sci. J. 8:IGY6-IGY20
Spies B, Frischknecht F (1991) 5. Electromagnetic sounding. Electromagnetic methods in applied geophysics. Number elSBN: 978-1-56080-268-6 print ISBN: 978-1-56080-022-4. https://doi.org/10.1190/1.9781560802686.ch5

Swidinsky A, Hölz S, Jegen M (2015) Rapid resistivity imaging for marine controlled-source electromagnetic surveys with two transmitter polarizations: an application to the North Alex mud volcano, West Nile Delta. Geophysics 80(2):E97-E110. https://doi.org/10.1190/geo2014-0015.1

Torta JM, Marsal S, Quintana M (2014) Assessing the hazard from geomagnetically induced currents to the entire high-voltage power network in Spain. Earth Planets Space 66:87. https://doi.org/10.1186/1880-5981-66-87

Torta JM, Marcuello A, Campany J, Marsal S, Queralt P, Ledo J (2017) Improving the modeling of geomagnetically induced currents in Spain. Space Weather 15:691-703. https://doi.org/10.1002/2017SW001628

Veeramany A, Unwin SD, Coles GA, Dagle JE, Millard DW, Yao J, Glantz CS, Gourisetti SNG (2016) Framework for modeling high-impact, low-frequency power grid events to support risk-informed decisions. Int. J. Disaster Risk Reduct. 18:125-137. https://doi.org/10.1016/j.jidrr.2016.06.008

Viljanen A, Pirjola R, Prácser E, Ahmadzai S, Singh V (2013) Geomagnetically induced currents in Europe: characteristics based on a local power grid model. Space Weather 11:575-584. https://doi.org/10.1002/swe.20098

Weidelt P, Chave AD (2012) The magnetotelluric response function. The magnetotelluric method. Cambridge University Press, Cambridge, pp $122-164$

Williams ML, Fischer K, Freymueller J, Tikoff B, Trehu A et al (2010) Unlocking the secrets of the North American continent: an EarthScope science plan for 2010 to 2020. EarthScope. https://doi.org/10.1002/swe.20073

\section{Submit your manuscript to a SpringerOpen ${ }^{\odot}$ journal and benefit from:}

- Convenient online submission

- Rigorous peer review

- Open access: articles freely available online

- High visibility within the field

- Retaining the copyright to your article

Submit your next manuscript at $\boldsymbol{\nabla}$ springeropen.com 